\title{
REFORMA E INOVAÇÃO EDUCATIVAS: O COTIDIANO COMO PERSPECTIVA DE ANÁLISE
}

\author{
REFORM AND EDUCATIONAL INNOVATION: \\ DAILY AS ANALYSIS EYESIGHT
}

\section{REFORMA E INNOVACIÓN EDUCATIVAS: EL COTIDIANO COMO PERSPECTIVA DE ANÁLISIS}

\author{
Antonio Serafim Pereira ${ }^{1}$ \\ Universidade do Extremo Sul Catarinense (UNESC), Criciúma/SC - Brasil ${ }^{1}$
}

\begin{abstract}
Resumo O presente trabalho põe em relevo os tópicos constitutivos da reflexão que empreendemos sobre reforma e inovação educativas na perspectiva do cotidiano escolar, muitas vezes obscurecidas pelos reformadores e pesquisadores interessados na proposição e/ ou análise de políticas educativas, tendo como referência Asperella (2013), Heller (1982, 2000), Rockwell (1997a, 1997b) e Zibas (1997), entre outras contribuições teóricas. Iniciamos tecendo considerações a respeito da reforma e inovação educativas e a problemática que as envolve. Em seguida, nos detemos de forma mais demorada na inovação educativa, salientando seu caráter político, cultural e cotidiano como subsídio para melhor compreender suas relações com as reformas educativas oficiais no que se refere aos seus destinos e impactos no interior das instituições escolares. Por fim, referimo-nos a algumas questões que abarcam a análise da inovação educativa, tendo o cotidiano escolar como perspectiva para analisá-la, compreendê-la e implementá-la.

Palavras-chave: Reforma; Inovação; Educação; Cotidiano escolar.
\end{abstract}

Abstract The present work highlights the constitutive topics of our reflection on educational reform and innovation in the perspective of everyday school life, often obscured by reformers and researchers interested in proposing and/or analyzing educational policies, having as reference Asperella (2013), Heller (1982, 2000), Rockwell (1997a, 1997b) and Zibas (1997), among other theoretical contributions. Next, we dwell more time on educational innovation, emphasizing its political, cultural and daily character as a subsidy to better understand its relations with the official educational reforms regarding their destinies and impacts within the school institutions. Finally, we refer to some issues that include the 
analysis of educational innovation, with the school daily life as a perspective for analyzing, understanding and implementing it.

Keywords: Reform; Innovation; Education; Everyday school.

Resumen El presente trabajo pone de relieve los temas constitutivos de la reflexión que emprendemos sobre reforma e innovación educativas, desde la perspectiva del cotidiano escolar, muchas veces, obscurecida por los reformadores e investigadores interesados en la proposición y/o análisis de políticas educativas, teniendo como referencia Asperella (2013), Heller (1982, 2000), Rockwell (1997a, 1997b) y Zibas (1997), entre otras contribuciones teóricas. En este sentido, empezamos a hacer consideraciones sobre la reforma educativa y la innovación y las cuestiones que les rodean. Iniciamos tejiendo consideraciones sobre reforma e innovación educativas y la problemática que las involucra. A continuación, nos detenemos de forma más demorada en la innovación educativa, subrayando su carácter político, cultural y cotidiano como subsidio para comprender mejor sus relaciones con las reformas educativas oficiales en lo que se refiere a sus destinos e impactos en el interior de las instituciones escolares. Por último, nos referimos a algunas cuestiones que abarcan el análisis de la innovación educativa, teniendo el cotidiano escolar como perspectiva para analizarla, comprenderla e implementarla.

Palabras clave: Reforma; La innovación; La educación; Cotidiano escolar.

\section{CONSIDERAÇÕES INICIAIS}

Podemos situar este trabalho, por sua característica básica, entre os que se configuram como reflexão/discussão teórica sobre o tema do qual se ocupam. No caso específico deste texto, versa acerca da reforma e inovação educativas - processo e análise - a partir da perspectiva do cotidiano escolar, tendo como referência Asperella (2013), Heller (2000), Rockwell (1997a, 1997b) e Zibas (1997), entre outras contribuições teóricas. Consideramos a pertinência de tal aporte no processo analítico dos aspectos que permeiam as relações sociais no contexto da escola, muitas vezes negligenciados pelos reformadores e pesquisadores que se ocupam, respectivamente, da proposição e análise de políticas educativas.

O potencial da análise por esse prisma tem sido evidenciado pela possibilidade que abre aos pesquisadores de se aproximarem da "grande diversidade de atividades mediante as quais os profissionais da educação, alunos e pais dão existência à escola dentro do contexto cultural que lhe circunscreve" (ROCKWELL, 1997b, p. 7). Além disso, por possibilitar-lhes apreender como o cotidiano escolar recebe e lida com as propostas reformadoras, de inovação e mudança das políticas educativas oficiais, muitas vezes de forte teor prescritivo e homogeneizador.

Buscando atender ao propósito anunciado, inicialmente tecemos considerações sobre reforma e inovação educativas: como as concebemos, de que modo se relacionam e a problemática que as envolve para se firmarem no cotidiano das escolas. Na sequência, reservamos 
espaço para um olhar mais atido à inovação, no sentido de ressaltar seu caráter cultural e cotidiano como subsídio para melhor compreender sua relação com as reformas educativas oficiais: seus destinos e impactos. Por fim, assinalamos algumas das questões que abrangem a análise da inovação educativa, tendo o cotidiano escolar como perspectiva para efetivá-la.

\section{REFORMA E INOVAÇÃO EDUCATIVAS: DIFERENCIAÇÃO OU APROXIMAÇÃO?}

A incursão revisitada que fizemos na literatura específica sobre reforma e inovação educativas confirma a difícil tarefa de tentar definir e/ou diferenciar esses dois termos, que têm se prestado, historicamente, a significados e propósitos pedagógicos, políticos e sociais muito diversos.

Para Popkewitz (1997, p. 22), a palavra reforma engloba diferentes conceitos, conforme os contextos históricos e as arenas das relações sociais. Sua posição é de "que não há uma definição permanente do termo e que seu significado sofre modificações dentro de um meio institucional em contínua transformação". Supõe o autor que a expressão reforma educativa possui significado variável, dependente do âmbito e da contribuição que empresta ao processo de mudança no ensino, na formação docente, no currículo ou nas ciências da educação. Defende a tese de que a reforma não tem uma definição essencial nem significa progresso, mas pode ser mais bem compreendida como parte do processo de regulação social. A retórica inovadora das reformas, que liga intenção com progresso (mudança), ignora os referentes políticos, econômicos e culturais daqueles que as propõem.

A reforma, segundo Deleuze (1993), é sempre uma proposição repressiva por parte de quem se oficia a representar e falar pelos outros. Visa mais a reorganização do poder do que, propriamente, produzir mudanças que beneficiem as pessoas ou entidades representadas (?) nos discursos. A mudança reivindicada pelos próprios interessados, resultante do questionamento à organização do poder constituído, para o autor, não é reforma, mas ação revolucionária.

De fato, a análise histórica vem apontando que, embora as reformas enunciem mudança no sentido positivo e qualitativo de melhoria da oferta educacional, acabam se convertendo em ritual e liturgia para justificar ou disfarçar as reais intenções dos reformadores "de fazer com que tudo se mova para que nada mude" (SACRISTÁN, 1999, p. 58). A exemplo de outros contextos, as reformas em nosso país têm originado choques cíclicos com efeitos inexpressivos e fugidios, que geram mais desilusão do que mudanças efetivas e reais.

Do mesmo modo, a inovação educativa tem sido alvo de definições plurais, conforme os interesses que movem as pessoas e as instituições. Como outros discursos e práticas sociais, possui um enredo próprio, explícito ou tácito, mas constituído de múltiplas compreensões. Podem as inovações, por conseguinte, apresentar-se como composições que se fecham às novas alternativas de mudança, mas também podem ser identificadas como textos provisionais e em aberto, diferentes e plurais, capazes de comporem novos significados e produzirem novas práticas e experiências contra-hegemônicas (SILVA, 1998). 
Isso nos dá a dimensão dos caminhos a que podem ser remetidos ambos os processos: "afiançamento, aperfeiçoamento recuperador ou mudança radical" (SACRISTÁN, 1998, p. 48). Reforma e inovação podem se constituir em mera adaptação aos consensos e exigências sociais vigentes para legitimá-los. Isto é, podem representar apenas uma simulação mudancista que além de não desenvolverem os processos e estratégias operacionais condizentes aos princípios teóricos que proclamam, camuflam suas reais intenções mediante o controle das consciências dos seus implicados (embora nem sempre consigam). Ou podem comportar mudanças educativas que representem respostas adequadas às transformações fundamentais da cultura escolar e social. Respostas comprometidas com o atendimento "à demanda popular por educação, por acesso à instrução e ao saber" (SOARES, 1988, p. 9), traduzidas em um projeto que reconhece a escola como conquista do povo (não doação) para manter vivo o sonho de se conseguir uma vida melhor. Um projeto inclusivo, não exclusivo (APPLE, 1996).

Embora nem sempre representem mudança real (transformação, melhoria, avanço), reforma e inovação aparecem, via de regra, relacionadas a esse intento, e nesse sentido se aproximam. Diferenciam-se, no entanto, conforme o compromisso ético e social que assumem em relação ao objeto de mudança. Por esse ângulo, perde relevância a preocupação excessiva em se distinguir reforma e inovação sob o critério da amplitude, gradação e incidência, que tem vinculado a primeira a macromudanças, visando atender aos fins e diretrizes básicas do sistema educativo e a segunda a mudanças de microespectro, limitadas ao cotidiano da escola e sala de aula (ESCUDERO; GONZÁLEZ, 1987; HERNÁNDEZ, et al., 1998).

Assume importância, portanto, a ideia de associação entre esses dois processos, quer por adesão, contestação ou oposição. Afinal, mudanças em educação não se produzem com total independência do sistema educativo e social no qual estão inclusas. Por conseguinte, reforma e inovação assumem entre si relação de complementaridade.

Assim, a falta de unanimidade em que ambas têm sido envolvidas no tocante à denominação e definição, precisão e delimitação não deve ser vista como problema, mas como indicação positiva para encararmos a definição desses dois termos a partir da noção de pertinência e sentido. Tal entendimento nos possibilitará captar a parcialidade e a retórica das suas definições. Do mesmo modo, facilitará a compreensão de seus contextos teórico-práticos determinados, interesses, subjetividades e complexidade, além de oportunizar apreender, como considera Pires (2011), seus potenciais para romper com os paradigmas tradicionais e/ou reconfigurar saberes e poderes que vêm se constituindo nos diferentes espaços educacionais. Por conseguinte, nos permitirá perceber que não há uma reforma ou inovação substantiva, "cujo perfil se ache universalmente feito" (FREIRE, 1993, p. 42), que precisamos nos interrogar de que reforma ou inovação estamos falando, pois que estas se definem pelos seus construtos e atributos específicos, concretamente situados e datados.

Não obstante essas considerações, conscientes de estarmos incorrendo em simplificação de alguma ordem, adotamos como definição de reforma o conjunto de políticas destinadas a produzir mudanças no sistema educacional, sejam elas gerais ou parciais, centraliza- 
das ou participativas, propostas pelo poder municipal, estadual ou federal. Como inovação nomeamos as iniciativas de mudança, que podem estar vinculadas ou não às diretrizes da reforma adstritas ao contexto da escola e da sala de aula. Por fim, demarcamos como mudança a alteração efetiva, que pode resultar da reforma/inovação ou da resistência a ela, da necessidade de articulá-la às particularidades do contexto da instituição a que se refere, da micropolítica da escola, da aprendizagem dos seus atores, entre outros elementos.

Definindo a mudança dessa forma, fazemos nosso bordão a posição de Torres (2000, p. 292) de que "nem toda reforma se traduz em mudança e nem toda mudança é resultado da reforma". Como bem discute, a mudança pode operar à margem da reforma, comumente desapercebida dos seus proponentes ou estudiosos, dando-lhe outra significação, diferente ou mesmo contrária. A mudança se produz resultante da discrepância entre expectativa e experiência que nos impele a mudar o pensamento, criar novo conhecimento e transformar a prática (BOLÍVAR, 2000). É que as escolas são organizações de relações e aprendizagens complexas em contínuo processo de mudança, que ultrapassam a lógica simplista do processo cartorial que tem caracterizado as reformas em educação. Por isso mesmo, capazes de ameaçar e desestabilizar os interesses oficiais, aproveitando-se das suas fragilidades para construir espaços contra-hegemônicos e mais democráticos (APPLE, 1999).

A riqueza desse movimento para se pensar em possibilidades que nos permitam romper com as pautas habituais não se apreende de fora do processo histórico cotidiano do contexto escolar, mas do centro dos seus acontecimentos - dos conflitos, das disputas, das manipulações, dos diálogos, das significações e representações culturais de seus atores sociais (HELLER, 2000).

\section{INOVAÇÃO EDUCATIVA: UM ESPAÇO A MAIS}

A análise das inovações em geral (de qualquer natureza ou amplitude) tem posto em evidência que todo processo inovador se consubstancia como tal a partir de uma situação que o justifique; da existência de contexto cultural, científico ou social favorável; de pessoas que o defendam e o concretizem; de meios ou estratégias que o tornem viável; da sua valorização e compreensão como elemento de reflexão, investigação e formação permanente (TORRE, 1994).

A inovação educativa, por sua própria natureza, constitui-se em processo complexo modulado por uma intrincada rede de dimensões políticas, sociais, pessoais, estruturais e simbólicas que comporta várias opções, como: a ideológica ou política, a teórica, a técnica, a cultural, a pessoal (ESCUDERO; GONZÁLEZ, 1987; GOLDBERG, 1989). Vale dizer: as inovações no contexto educacional têm sido determinadas por circunstâncias históricas, sociais, econômicas e culturais, que podem emergir por força de um movimento de resistência, transgressão ou ruptura (ALBARRACIN; SILVA; SCHIRLO, 2013), mas também de simples adaptação ou enquadramento às diretrizes propostas por reformas educativas/ curriculares pensadas sem o devido e necessário diálogo democrático com as entidades 
representativas dos profissionais da educação e da sociedade civil.

Segundo Warde; Ribeiro (1989, p. 195), a inovação educacional "só ganha significação quando examinada como parte do processo histórico-social", que transcende a análise de caráter técnico-pedagógico. Recomendável é que seja analisada a partir do contexto local e global da sociedade em que se desenvolve, além da forma como as pessoas nela envolvidas se colocam, sejam as que promovem, coordenam, praticam ou dela recebem seus efeitos. Isso implica considerarmos que à ideia geral de inovação como introdução de algo novo em uma dada organização educativa, visando modificá-la, há de se incorporar a de que a definição do que seja uma inovação depende de como as pessoas que a ela se relacionam a veem.

Todavia, os estudos e investigações nessa área têm nos oferecido, pelo menos, três imagens básicas: inovação como sistema de mudança, inovação como solução de problemas e inovação como crescimento. Isto é, o fenômeno inovador tem sido visto como processo organizado que ora pode originar-se de plano de mudança previamente pensado para ser executado, ora pode decorrer de uma situação problemática que se impõe como necessidade a ser solucionada ou constituir-se em instrumento de aprendizagem para a organização e para as pessoas que, de alguma forma, a ela estão vinculadas.

A inovação, enquanto processo que envolve conhecimento, comporta duas ações interligadas: a desconstrução e a reconstrução (DEMO, 2000). A primeira decorre do questionamento sobre o que está culturalmente sacramentado. Este, por sua natureza crítica, radiografa o contexto em suas possibilidades e fragilidades, buscando não só compreendê-lo, mas reconstruí-lo. Falamos de um questionamento eticamente comprometido e uma reconstrução coletivamente produzida, aberta ao provisório, à pesquisa e ao aprender permanente. Uma reconstrução permeável à crítica desconstrutiva, que se reconstrói, dialeticamente, num processo de incessante inovar-se, engajado no movimento de emancipação das pessoas.

Nesse sentido, vale a consideração de Heller (1982, p. 137) de que "a tradição possui uma força imensa, sobretudo sobre a vida cotidiana", o que exigirá compreensão clara por parte dos protagonistas da inovação sobre seus carecimentos e do esforço que precisarão empreender no tocante à desconstrução e reconstrução necessárias à transformação almejada com vistas à melhor qualidade social da educação e da vida.

Os movimentos atuais que objetivam a inovação educativa têm se constituído em uma reação ao currículo apresentado ao professor, como assinala Sacristán (1998), ou como resposta à crise da mudança programada, como prefere Bolívar (2000). Tais movimentos buscam resgatar o protagonismo do professor e da escola no processo de mudança em oposição aos modelos "sugeridos" sem o diálogo com os seus principais interessados, como foi o caso dos Parâmetros Curriculares Nacionais do Ensino Fundamental (PCNEF) propostos pelo Ministério da Educação brasileiro, denunciados pelos docentes da UFRGS (FACULDADE DE EDUCAÇÃO DA UNIVERSIDADE FEDERAL DO RIO GRANDE DO SUL, 1997).

Do modelo de Desenvolvimento Organizativo dos anos 1970 ao das Escolas Eficazes/ Revisão Baseada na Escola (1980), de Gestão Baseada na Escola/Reestruturação Esco- 
lar (1990) ao da Aprendizagem Organizativa, proposto nos anos 2000 (BOLÍVAR, 2000), apreendem-se aspectos comuns que os caracterizam, a saber: escola como unidade de mudança; mudança como processo de aprendizagem; mobilização das potencialidades e condições internas, visando mudança na cultura escolar; integração de estratégias diversas de inovação (internas e externas); institucionalização da mudança como objetivo último; formação dos docentes no próprio contexto de trabalho; cumprimento qualitativo das metas educativas objetivando a melhoria da aprendizagem dos alunos.

Contudo, não escapam a Bolívar (2000) as diferenças e críticas que extrai desses enfoques na defesa da teoria que cognomina com Fullan e Hargreaves (2000), entre outros, de Aprendizagem Organizativa. Conforme o autor, o Desenvolvimento Organizativo constitui-se em uma teoria intervencionista de mudança (de fora para dentro), que se sucede enquanto subsiste o interesse do seu promotor, ainda que aposte no envolvimento dos implicados. O movimento das Escolas Eficazes, por sua vez, tem se fixado nas estratégias para incrementar os resultados da aprendizagem dos alunos, sem questioná-los, secundarizando a análise do processo de mudança. A Revisão baseada na Escola, apesar de arrogar-se uma reconstrução educativa do Desenvolvimento Organizativo por dirigir-se à capacitação da escola e dos professores para a solução de seus problemas, tem se detido no como mudar em detrimento do que mudar.

Nos anos 1990, os governos ocidentais, em uma síntese das teorias anteriores, incorporam às políticas educacionais o discurso da autorrenovação da escola, empunhando como slogans: autonomia escolar, gestão local do projeto pedagógico, racionalização e otimização de recursos, clima democrático, capacitação profissional em serviço, projetos participativos e interdisciplinares etc. Os movimentos de Gestão baseada na Escola e de Reestruturação Escolar passam, então, a sustentar os princípios e interesses neoliberais que defendem projetos locais a custo mínimo, mas capazes de retroalimentar o mercado, transferindo, assim, cada vez mais, a responsabilidade do Estado (principalmente a financeira) com a educação obrigatória para as esferas locais (município, comunidade, escola).

Além disso, analisa Bolívar (2000, p. 66), o fascínio que essas propostas despertam, pela sua apologia à participação, tem sido desproporcional à sua incidência real para transformar o ensino em sala de aula: "há uma falta de conexão entre as estruturas organizativas da escola e os processos de ensino-aprendizagem". Na sua visão, autonomia e descentralização nas decisões são importantes, mas insuficientes para comprometer os principais agentes a um processo coletivo de aprendizagem em prol do desenvolvimento da escola.

Nesse sentido, Bolívar (2000) tem defendido que o núcleo da mudança educativa se situa no espaço intermediário entre a sala de aula e as estruturas do sistema, que são as condições organizativas da escola, em cujo complexo está a força dos conhecimentos, significados, representações e práticas dos professores, que formam a cultura escolar instituída. Por aqui é que deve começar a mudança. A leitura e o debate desse componente nos apontarão os indicadores-chave de uma inovação suscetível de garantir a melhoria da aprendizagem de todos; em última instância, dos alunos.

Assim, a inovação educativa está imbuída em construir coletivamente a redireção da escola a partir do que está em desenvolvimento para reculturalizá-la, usufruindo dos 
subsídios que fornecem os professores e alunos como aprendizes, as outras escolas, a comunidade e o contexto político social (Aprendizagem Organizativa). Nessa abordagem, os coordenadores da mudança têm o papel de contribuir para que seus envolvidos busquem sentidos que redirijam a mudança pretendida, ressituem suas rotinas, alterem significados por novas linguagens e identidades e se conscientizem de que cada um representa o propósito da mudança a partir da sua ótica. Ao invés de condená-las, melhor aprender com elas.

\section{INOVAÇÃO EDUCATIVA E O COTIDIANO ESCOLAR}

Os estudos sobre inovação têm dado ampla visibilidade à esguelha parcializadora dos diferentes enfoques explicativos do processo inovador, convocando-nos a colocá-la no campo da análise cotidiana e interdisciplinar para melhor compreendê-la.

A inovação educativa, acima de tudo, não pode ser pensada como um corpo unidimensional, mas como uma teia de relações que a fazem una e múltipla, simultaneamente. Assim, a inovação precisa ser pensada e produzida por "várias mãos e sua leitura pressupõe o entendimento não apenas de suas conexões com a sociedade" (RESENDE, 1997, p. 91), mas também com o espaço cotidiano da escola. Isso, por si só, nos intima a visualizar o processo inovador como uma totalidade, que vai do compromisso político à competência técnica (MELLO, 1982). Não só o aspecto técnico, cultural ou sociopolítico isoladamente definindo a inovação; nenhum deles rejeitando, reduzindo e/ou se sobressaindo sobre o outro, parcializando a inovação, mas o desmoronamento de qualquer fronteira que territorializa cada aspecto considerado (MORIN, 1982; SANTOMÉ, 1998).

Aliás, como acentuam, apropriadamente, Escudero; González (1987), a consideração conjunta das diferentes dimensões da mudança escolar é deveras conveniente para que se possa captar, de forma mais compreensiva, a dinâmica dos diferentes elementos que interatuam na sua constituição. No processo inovador, a interfecundação dos diferentes campos conceituais, que concorrem para a sua significação (ou representação) evitará enviesá-la em abordagens e enfoques fragmentários. Também nos ajudará a entender, como pontua Carneiro (2000, p. 93), que "o novo é construído na transversalidade daquilo que já está instituído". A tradição serve como contexto e referência para a mudança pretendida, o que significa dizer que mudança global e absoluta não existe. Assim inovação, mudança e tradição são, consideravelmente, interdependentes e, necessariamente, dialogais.

Esse argumento tem sustentação em Sirotinik (1994), por exemplo. Primeiro, pela denúncia que faz ao reducionismo da tradição técnico-prescritiva predominante nos processos inovadores. Segundo, porque defende que, para compreender a inovação ancorada na escola é preciso olhá-la a partir das suas coordenadas epistemológica, organizativa, experiencial e ecológica, que se complementam mutuamente.

Tem também apoio em Rocha (1997, p. 26), que, inspirado no processo de reestruturação curricular das escolas da rede municipal de educação de Porto Alegre, capital do Rio Grande do Sul (Brasil), nos anos 1990, concebe a inovação curricular "como um fenômeno 
histórico, resultado de forças sociais, políticas e pedagógicas que expressam a organização dos saberes vinculados à construção de sujeitos sociais", que não se satisfaz em apenas discutir programas, conteúdos, cargas horárias, recursos, porque experiências dessa ordem já foram várias vezes realizadas, sem que de fato a escola tenha se modificado. Defende, por isso, que a inovação tem a ver com todos esses fatores técnico-administrativos, mas nela também deverão estar contemplados, em uma relação de reciprocidade, os demais aspectos que compõem a totalidade social e da escola.

A análise de um processo complexo como a inovação educativa não pode ficar aprisionada a umas poucas categorias (oficial, tecnológica, psicológica, pedagógica), que acabam por estreitar a compreensão do que ocorre no seu interior. Nem mesmo pode ficar presa à abordagem sociocrítica marxista, que a par da sua importância para analisar o currículo e sua relação com a economia e a produção, converte-se num enfoque exclusivo, desde uma perspectiva política e ideológica, descuidando-se dos aspectos tecnológicos e de significação (TORRE, 1994). Precisa, portanto, colocar-se permeável a outros olhares e conceitos capazes de ampliar (não afunilar) a compreensão dos sentidos que transdimensionam a inovação educativa como globalidade.

Via de regra, o que se confirma no campo das políticas públicas, em especial na América Latina, é que a reforma e/ou inovação que propõem os setores oficiais são construídas fora do contexto cultural das instituições escolares. Ou seja, são produzidas para a escola e não com a escola (ASPERELLA, 2013). O caráter prescritivo das reformas e inovações educativas contemporâneas, para Zibas (1997, p. 121), tem sido responsável pela baixa repercussão na experiência cotidiana das escolas, por se gestarem e se desenvolverem "à margem da história [...], da cultura e das necessidades da maioria da população, ignorando também a prática, o conhecimento, a formação e a vivência dos professores".

Segundo Asperella (2013), a inversão dessa lógica possibilitaria que a escola e sua cotidianidade se constituíssem em espaço, por excelência, de produção de políticas públicas. Desse modo, como tradução dos anseios, necessidades e possibilidades cotidianos, as reformas/inovações educativas ou culturais, como sugere o autor nesse caso, teriam maiores chances de ser mais bem compreendidas e incorporadas às práticas pedagógicas das escolas por seus agentes sociais. Assim, o protagonismo dos principais envolvidos, "a partilha de poderes e saberes em situações de ensino-aprendizagem, o respeito e a descoberta, tanto por parte dos professores quanto de alunos, dos pressupostos filosóficos e ontológicos que presidem o conhecer" (LEITE; GENRO; BRAGA, 2011, p. 37), entre outros fatores, dariam suporte para a gestão das instabilidades e descontinuidades a que tais processos estão sujeitos.

De todo modo, articuladas ou não à experiência cotidiana das escolas, importa destacar a advertência de Rockwell (1997b), para quem as políticas educativas influenciam o cotidiano escolar, mas não o determinam. Propostas (impostas?) pelos órgãos centrais, as prescrições e orientações nelas contidas são reinterpretadas pela escola nos termos de sua cultura institucional. Dessa maneira, a natureza das mudanças gestadas em seu contexto particular pode ser imprevisível no que diz respeito aos programas oficiais, podendo, entre outras direções, divergir das pretensões proclamadas/esperadas. Confirma-se, nesse senti- 
do, o pensamento de Heller (2000) de que as mudanças sociais, em particular as da área da educação, resultam das probabilidades, que podem emergir das atividades humanas empreendidas e suas consequências, cuja previsibilidade é incerta e qualquer mensuração precisa, improvável. Afinal, projetos inovadores estão sujeitos a equívocos de intenções, expectativas, práticas e cálculos por serem movimentos/espaços repletos de riscos face às disputas de poder, significações e representações dos que neles estão envolvidos (BAUMAN, 2005).

Tal assertiva se evidenciou na decisão tomada, circunstancialmente, por uma escola pública estadual do litoral norte gaúcho (Rio Grande do Sul), na década de 1990, em produzir, coletivamente, uma proposta político-pedagógica alternativa como resistência à reforma educacional do governo da época (1991-1994), interpretada como retrocesso à democratização da escola pública conquistada, pela imposição de calendário escolar rotativo; retorno à indicação dos gestores escolares; ênfase na racionalização dos recursos materiais e humanos (salas de aula cheias, desmantelamento das equipes pedagógicas e de apoio); perseguição ao movimento sindical dos trabalhadores em educação, entre outras medidas. O clima de tensões desencadeado por tais medidas "foi, sem dúvida, o estopim para a reorganização dos professores no interior da Escola. Por um lado, para resgatar seus direitos profissionais e, por outro, para resguardar o direito de serem ouvidos para fazer uma escola pública mais autônoma e cidadã” (PEREIRA, 2007, p. 227).

A mencionada proposta político-pedagógica (elaborada coletivamente) - inédita na escola por seu caráter autônomo e inovador - foi alvo de nossa análise fundamentada no propósito de realizar uma pesquisa com os professores, não para eles ou sobre eles. Uma pesquisa significativa e necessária com vistas a favorecer-lhes uma reflexão aprofundada e crítica sobre os sentidos que vinham atribuindo às suas vivências profissionais como protagonistas da inovação em desenvolvimento.

Objetivando nos aproximar do contexto cotidiano da inovação e da escola, na fase exploratória da pesquisa buscamos, nos documentos institucionais, relatórios da própria proposta, e nos questionários aplicados aos docentes, dados preliminares sobre o processo inovador em movimento. A discussão com a direção, equipe pedagógica e os professores acerca dos dados que emergiram desses instrumentos, fortaleceu e ampliou a descrição e a crítica da realidade escolar e da inovação, subsidiando a delimitação do objeto de estudo: a interdisciplinaridade (um dos princípios eleitos para nortear o currículo escolar), apontada pelos professores como necessidade a ser enfrentada em relação ao ensino. Interessava-lhes compreender melhor o processo interdisciplinar para qualificar a prática docente. Definimos, dessa maneira, que o estudo teria caráter de descrição, compreensão e aprendizagem, afinado com os pressupostos de uma pesquisa qualitativa de cunho etnográfico, dada sua pertinência à análise do contexto a ser investigado, tendo o cotidiano como categoria analítica.

Foi, portanto, na fase processual da pesquisa que o cotidiano se descortinou com seus desejos, resistências, disputas, conflitos, representações, significações; suas permanências, continuidades, rupturas, ressignificações, fragilidades e possibilidades, especialmente em relação à interdisciplinaridade, a partir de nosso acompanhamento em sala de aula e demais espaços escolares (observação participante). As entrevistas semiestruturadas - com profes- 
sores, diretora, representantes da equipe pedagógica e coordenadores de projetos específicos -, constituídas com base nas notas de campo geradas no processo de observação dos espaços nomeados (análise), permitiram-nos: a) aprofundar suas compreensões acerca da interdisciplinaridade (como a significavam e como a viam na prática); b) refletir com eles a respeito de seus saberes e práticas; c) acolher suas manifestações acerca da importância da pesquisa para o trabalho que desenvolviam e a necessidade de nossa mediação para ajudá-los no seu aperfeiçoamento (PEREIRA, 2007).

Em suma, pela experiência investigativa vivenciada apreendemos que os participantes da pesquisa estavam envolvidos em um processo de inovação comprometido em "desestabilizar o pensar reprodutivo e instalar em seu lugar a inquietação, a ansiedade pelo saber mais, pelo entender o que não se entende, por compreender pontos de vista que à primeira vista podem parecer distanciados entre si" (LEITE; GENRO; BRAGA, 2011, p. 25-26).

Destarte, é conveniente que a pesquisa concernente às políticas educativas, como argumenta Asperella (2013), busque, a partir da perspectiva do cotidiano escolar, apreender, analisar e compreender as tensões produzidas nas relações sociais estabelecidas nos diferentes âmbitos da experiência educativa. Nesse sentido, o autor recomenda ao pesquisador “considerar, entre outras, categorias referentes à cultura institucional; à própria prática; à apatia das instituições e estruturas sociais; à construção da subjetividade e do processo de reprodução social"' (ASPERELLA, 2013, p. 101). Nessa perspectiva, destaca três focos que pondera como importantes - pela relevância social e contradições de suas práticas, em particular na América Latina - na análise das práticas políticas de educação: democratização das práticas educativas; descentralização e autonomia escolar; papel dos profissionais da educação nos processos de reforma e inovação educativa.

A pesquisa também poderá deter-se em descrever/analisar, como prefere Rockwell (1997b, p. 19), de forma mais específica, as dimensões da experiência escolar cotidiana (estrutura organizacional/relacional; concepções do trabalho docente; conhecimento escolar - organização e articulação com o saber popular; definição da aprendizagem escolar e concepções de mundo), sem perder de vista seu caráter diverso/global e sua articulação com os processos sociopolítico-culturais para captar "o sentido histórico particular do que acontece nas escolas".

\section{ConsideraÇões finais}

Enfim, a perspectiva cotidiana confirma/reafirma a tese de que a inovação educativa, quer no plano do seu desenvolvimento, quer no plano participativo das pessoas, é única, conflitante e complexa nos seus valores e decisões e, por isso mesmo, sem condições de ser englobada por uma única e reconhecida teoria que, pretensiosamente, se disponha a fundamentar e dirigir, de forma unívoca e linear, o rumo dos seus acontecimentos (PÉREZ GÓMEZ, 1998).

Assim como toda forma de conhecimento não é em si mesma exaustiva, mas tenta o diálogo com outras fontes do saber, deixando-se irrigar por elas (FAZENDA, 1995), a 
inovação também o é, especialmente na área em que estamos nos concentrando. Há na inovação uma espécie de circuito relacional (MORIN, 1977), isto é, os seus elementos constitutivos (partes) se interligam à sua propriedade global (todo) e vice-versa. Importa, pois, conhecermos as qualidades das contribuições e regulações, que estão inibidas e invisíveis na inovação, para que possamos perceber o que estimula ou inibe as mudanças pretendidas no campo educacional.

Não obstante, o diálogo e a quebra de fronteiras entre os diferentes enfoques, narrativas e conceitos representem o eixo-mestre da inovação, tal não se consubstancia como pressuposto suficiente. A inovação precisa apresentar-se, também, como possibilidade de produzir novas aprendizagens e conhecimentos, novas inter-relações, novas histórias, inclusive novas abordagens. Necessita, por conseguinte, constituir-se em espaço e esfera pública de cidadãos cruzadores de fronteiras, capazes de exercerem o poder sobre suas vidas e, especialmente, sobre as condições de produção e aquisição de conhecimentos (GIROUX; MCLAREN, 1995).

A inovação educativa que concebemos não se identifica com aquela elaborada por pessoas que se dizem representantes ou que têm a ocupação de falar pelos outros - o tradutor/especialista - mas se refere à reivindicada e exigida por aqueles a quem ela diz respeito. Uma inovação, portanto, em que as pessoas a quem ela concerne pensem o próprio pensamento, conheçam o próprio conhecimento (BONAFÉ, 1995), falem por elas próprias; que não desqualifique (qualifique) o saber dos sujeitos interessados nela; que se traduza numa parceria por meio da qual os assessores e intelectuais externos assumam o compromisso de contribuir para mudar o regime político, econômico e institucional de produção da verdade, jamais mudar o que as pessoas têm na cabeça. Conforme Foucault (1993, p. 14),

\footnotetext{
...não se trata de libertar a verdade de todo sistema de poder - o que seria quimérico na medida em que a própria verdade é poder - mas de desvincular o poder da verdade das formas de hegemonia (sociais, econômicas, culturais) no interior das quais ela funciona no momento.
}

Pelo visto, as possibilidades do caráter dialógico e emancipatório da inovação educativa como ação social e como conhecimento coletivo precisam ser questionadas e (re) interpretadas, pois num grupo nem todas as vozes possuem o mesmo valor. O que as faz ter ou não poder depende "de quem as produz, onde, quando e como" (COSTA, 1998, p. 246). Além do que, poder falar, muitas vezes, não quer dizer autoria, conscientização, autonomia, emancipação. Discursos colonizadores que se apropriam das vozes dos sujeitos fazem desaparecer as singularidades/identidades dos que falam. Por isso mesmo, uma relação dialógica não necessariamente garante a participação democrática.

No entanto, o fato de não termos essas garantias democráticas não invalida qualquer projeto inovador participativo, especialmente em educação. Processos inovadores com possibilidades reais de se efetivarem com todos os seus avanços e retrocessos, encontros e desencontros, continuidades e descontinuidades serão aqueles "que se abram para a diversidade, acolham as diferenças e incentivem a que múltiplas leituras do mundo reivin- 
diquem voz e espaço para nomeá-lo" (COSTA, 1998, p. 254). A nosso ver, as inovações que objetivam produzir novas alternativas, construídas na contramão do poder constituído, podem sinalizar novas possibilidades capazes de fortalecer o direito humano à educação, conjugado ao acesso e à qualidade emancipatória.

\section{REFERÊNCIAS}

ALBARRACIN, E. S.; SILVA, S. C. R.; SCHIRLO, A. C. Interdisciplinaridade e inovação educativa: saberes e práticas. Simpósio Internacional sobre Interdisciplinaridade no Ensino, na Pesquisa e na Extensão - Região Sul. Florianópolis: UFSC, 2013. Disponível em: http://www.siiepe.ufsc.br/artigos-selecionados/, 2013<hal-01057572> Acesso em: $12 / 12 / 2017$.

APPLE, M. W. Entrevistas com os intelectuais. In: LINHARES, C. F.; GARCIA, R. L. (Orgs.). Dilemas de um final de século: o que pensam os intelectuais. São Paulo: Cortez, 1996, p. 73-114.

. Conhecimento oficial: a educação democrática numa era conservadora. Petrópolis, RJ: Vozes, 1999.

ASPERELLA, G. La interpelación de lo cotidiano a las políticas educativas (políticas educativas, reformas y vida escolar cotidiana). In: TELLO, C. (Coord. y Compilador). Epistemologías de la política educativa: posicionamientos, perspectivas y enfoques. Campinas, SP: Mercado de Letras, 2013, p. 91-108.

BAUMAN, Z. Vidas desperdiçadas. Rio de Janeiro: Jorge Zahar, 2005.

BOLÍVAR, A. Los centros educativos como organizaciones que aprenden: promesa y realidades. Madrid: La Muralla, 2000.

BONAFÉ, J. M. El profesorado en el tercer milenio. Cuadernos de Pedagogía, 240, 1995, p. 23-28.

CARNEIRO, V. C. Mudanças na formação de professores de matemática: um estudo de caso. Zetetiké, n. 13/14, v. 8, 2000, p. 81-116.

COSTA, M. V. A pesquisa-ação na sala de aula e o processo de significação. In: SILVA, L. H. (Org.). A escola cidadã no contexto da globalização. Petrópolis, RJ: Vozes, 1998, p. 239-256. 
DELEUZE, G. Os intelectuais e o poder: conversa entre Michel Foucault e Gilles Deleuze. In: FOUCAULT, M. Microfísica do poder. Rio de Janeiro: Graal, 1993, p. 69-78.

DEMO, P. Ironias da educação: mudança e contos sobre mudança. Rio de Janeiro: DP\&A, 2000.

ESCUDERO, J. M.; GONZÁLEZ, M, T. G. Innovación educativa: teorías e procesos de desarrollo. Barcelona: Humanitas, 1987.

FACULDADE DE EDUCAÇÃO DA UNIVERSIDADE FEDERAL DO RIO GRANDE DO SUL. Análise do Documento Parâmetros Curriculares Nacionais. In: SILVA, L. H.; AZEVEDO, J. C.; SANTOS, E. S. Novos mapas culturais, novas perspectivas educacionais. Porto Alegre: Sulina, 1997, p. 121-136.

FAZENDA, I. C. Interdisciplinaridade: um projeto em parceria. São Paulo: Loyola, 1995.

FOUCAULT, M. Vigiar e punir: história da violência nas prisões. Petrópolis, RJ: Vozes, 1993.

FREIRE, P. Política e educação. São Paulo: Cortez, 1993.

FULLAN, M.; HARGREAVES, A. A escola como organização aprendente: buscando uma educação de qualidade. Porto Alegre: ArtMed, 2000.

GIROUX, H.; MCLAREN, P. Formação do professor como uma contra-esfera-pública: a pedagogia radical como uma forma de política cultural. In: MOREIRA, A. F. e SILVA, T. T. (Orgs.). Currículo, cultura e sociedade. São Paulo: Cortez, 1995, p. 125-154.

GOLDBERG, M. A. A. Inovação educacional: a saga de sua definição. In: GARCIA, W. E. (Coord.). Inovação educacional no Brasil: problemas e perspectivas. São Paulo: Cortez/ Autores Associados, 1989, p. 183-194.

HELlER, A. Para mudar a vida: felicidade, liberdade e democracia. São Paulo: Brasiliense, 1982.

. O cotidiano e a história. São Paulo: Paz e Terra, 2000.

HERNÁNDEZ, H. et al. Aprendiendo de las innovaciones en los centros: a perspectiva interpretativa de investigación aplicada a tres estudios de caso. Barcelona: OCTAEDRO, 1998.

LEITE, D.; GENRO, M. E. H.; BRAGA, A. M. S. B. Inovações pedagógicas e demandas ao docente na universidade. In: . (Orgs.). Inovação e pedagogia universitária. Porto Alegre: Editora da UFRGS, 2011, p. 19-48. 
MELLO, G. N. Magistério de $\mathbf{1}^{\mathbf{0}}$. grau: da competência técnica ao compromisso político. São Paulo: Cortez/Autores Associados, 1982.

MORIN, E. La méthode, la nature de la nature, (t. 1). Seuil: Edição de bolso, coleção, Points, 1977.

Science avec conscience. Paris: Fayard, 1982.

PEREIRA, A. S. Análise de um processo de inovação educativa numa escola gaúcha: a interdisciplinaridade como princípio inovador. Santiago de Compostela/Espanha. Serviço de Publicações e Intercâmbio Científico/Universidade de Santiago de Compostela, 2007 (tese de doutoramento).

PÉREZ GÓMEZ, A. I. Compreender o ensino na escola: modelos metodológicos de investigação educativa. In: SACRISTÁN, J. G. e PÉREZ GÓMEZ, A. I. Compreender e transformar o ensino. Porto Alegre: ArtMed, 1998, p. 99-117.

PIRES, R. C. M. Inovação e avaliação no marco da crise do Estado e da universidade pública. In: LEITE, D.; GENRO, M. E. H.; BRAGA, A. M. S. B. (Orgs.). Inovação e pedagogia universitária. Porto Alegre: Editora da UFRGS, 2011, p. 49-63.

POPKEWITZ, T. S. Reforma educacional: uma política sociológica - poder e conhecimento em educação. Porto Alegre: ArtMed, 1997.

RESENDE, L. M. G. Paradigma - relações de poder - projeto político-pedagógico: dimensões indissociáveis do fazer educativo. In: VEIGA, I. P. Projeto político-pedagógico da escola: uma construção possível. Campinas, SP: Papirus, 1997, p. 53-94.

ROCHA, S. Novas perspectivas educacionais: caminhada coletiva de reestruturação curricular nas escolas municipais de Porto Alegre. In: SILVA, L. H.; AZEVEDO, J. C.; SANTOS, E. S. (Orgs.). Novos mapas culturais e novas perspectivas educacionais. Porto Alegre: Sulina, 1997, p. 260-272.

ROCKWELL, E. Introducción. In: . (Coord.). La escuela cotidiana. México: Fondo de Cultura Económica, 1997a, p. 7-11.

. De huellas, bardas y veredas: una historia cotidiana en la escuela. In:

(Coord.). La escuela cotidiana, México: Fondo de Cultura Económica, 1997b, p. 13-57.

SACRISTÁN, J. G. O currículo: uma reflexão sobre a prática. Porto Alegre: ArtMed, 1998. 
. Reformas educacionais: utopia, retórica e prática. In: SILVA, T. T.; GENTILI, P. (Orgs.). Escola S.A.: quem ganha e quem perde no mercado educacional do neoliberalismo. Brasília, DF: CNTE, 1999, p. 50-74.

SANTOMÉ, J. T. Globalização e interdisciplinaridade: o currículo integrado. Porto Alegre: ArtMed, 1998.

SILVA, T. T. Currículo e identidade social: territórios contestados. In: SILVA, T. T. (Org.). Alienígenas na sala de aula: uma introdução aos estudos culturais em educação. Petrópolis, RJ: Vozes, 1998, p. 190-207.

SIROTINIK, K. A. La escuela como el centro del cambio. In: ESCUDERO, J. M.; GONZÁLEZ, M. T. G. (Orgs.). Profesores y escuela: ¿hacia una reconversión del centros y la función docente? Madrid: Ediciones Pedagógicas, 1994.

SOARES, M. Linguagem e escola: uma perspectiva social. São Paulo: Ática, 1988.

TORRE, S. Innovación curricular: procesos, estrategias e evaluación. Madrid: Dykinson, 1994.

TORRES, R. M. De agentes de la reforma a sujetos del cambio: la encrucijada docente en América Latina. Perspectivas, vol. XXX, n. 2, Paris, 2000, p. 281-299. Disponível: http:// repositorio.minedu.gob.pe/bitstream/handle/123456789/2974/agentes de reforma_sujetos_cambio torres.pdf? sequence=1 Acesso: 12/10/2017.

WARDE, M. J. O Colégio de Aplicação da Universidade de São Paulo. In: GARCIA, W. E. (Coord.). Inovação educacional no Brasil: problemas e perspectivas. São Paulo: Cortez/ Autores Associados, 1989, p. 101-131.

ZIBAS, D. M. L. ¿Un juego de espejos rotos? La vida escolar cotidiana y las políticas educativas en América Latina. Revista Iberoamericana de Educación, n. 15, sep./dic. 1997, p. 121-137. Disponível em: https://rieoei.org/historico/oeivirt/rie15a05.htm Acesso em: 10/10/1017.

Dados do AUtor:

Antonio Serafim Pereira

Pós-doutor em Ciências Humanas e Sociais pela Universidade de Buenos Aires, Argentina. Doutor em Educação pela Universidade de Santiago de Compostela, Espanha. Docente pesquisador da Universidade do Extremo Sul Catarinense. Coordenador do Grupo de Estudos e Pesquisa sobre Formação e Gestão na Educação Básica. Criciúma/SC - Brasil. asp@unesc.net

Submetido em: 14-5-2018

Aceito em: 7-12-2018 